\title{
The effect of United Kingdom immigration policies on migrant access to sexual and reproductive healthcare
}

\author{
Isabelle Whelan
}

\section{Correspondence to}

Isabelle Whelan, St George's, University of London, London SW17 ORE, UK; m1600067@ sgul.ac.uk

Received 18 June 2018 Revised 10 September 2018 Accepted 18 September 2018 Published Online First 20 October 2018
Check for updates

(C) Author(s) (or their employer(s)) 2019. No commercial re-use. See rights and permissions. Published by BMJ.

To cite: Whelan I. BMJ Sex Reprod Health

2019;45:74-77.

\section{INTRODUCTION}

The Faculty of Sexual \& Reproductive Healthcare has stated that there is "no health without sexual and reproductive health". ${ }^{1}$ While this is an admirable ambition, for many migrants to the UK the introduction of upfront charging for some services and an agreement to share data between the National Health Service (NHS) and the Home Office, the department of the UK government responsible for immigration, security and policing, threaten their ability to access treatment, endangering their health and having potential wider consequences for public health.

The 2014 Immigration Act mandated that patients deemed to be "overseas visitors" must pay for some aspects of NHS care in England. Since October 2017, NHS trusts have been required to withhold treatment from chargeable patients unless payment is received in advance. ${ }^{2}$ During the same period, NHS Digital, the national information and technology partner organisation to the health and care system, and the Home Office signed an agreement whereby confidential patient information could be shared with the authorities in immigration cases.

Upfront charges can be deferred, but are not waived, for 'immediately necessary' treatment that a patient needs promptly to save their life, to prevent a condition from becoming immediately life-threatening, or to prevent permanent serious health damage from occurring; or for 'urgent care', treatment that is not 'immediately necessary' but which cannot wait until the person can reasonably be expected to leave the UK. ${ }^{2}$ For non-urgent treatment, various categories of patient and categories of care are also exempted, including sexual health and family planning services.
However, in practice both the policies above are likely to have serious ramifications for patients who may need those services. While these issues apply across the NHS, they are salient to highlight in sexual and reproductive healthcare (SRH) because they undermine the exemption from charging in these areas.

\section{BACKGROUND}

\section{Overseas visitors charging regulations}

Overseas visitors are defined as 'any person not ordinarily resident in the UK'. ${ }^{2}$ The 2014 legislation also introduced a health surcharge of $£ 200$ for each year for which a visa is granted, payable in advance, for temporary migrants from outside the European Economic Area, which entitles them to the same NHS access as people who are ordinarily resident. In February 2018, the government announced that the surcharge is to double to $£ 400$ a year. 'Chargeable' patients are primarily undocumented migrants or short-term visitors, but people often move from one migrant status to another.

A complex list of services and conditions are exempt from payment for non-urgent care, as are particular groups of patients such as asylum seekers and refugees. Treatment for physical or mental health conditions related to torture, female genital mutilation, domestic violence or sexual violence is also exempt. ${ }^{2}$ Accident and Emergency services and primary care are currently not chargeable.

\section{Data sharing}

In addition to the charging regime, in 2017 NHS Digital and the Home Office signed a memorandum of understanding $(\mathrm{MoU})$ to share information about patients for the purposes of immigration enforcement. Organisations working in this area, 
including the National Aids Trust and Doctors of the World, have articulated their fear that this policy will discourage patients from accessing care, arguing that the data-sharing agreement fundamentally undermines the confidentiality that is at the heart of a safe and effective health system. ${ }^{3}$ They note that the General Medical Council's own guidance on confidentiality explicitly highlights the potential deterrent effect of breaching confidentiality: "Patients may avoid seeking medical help, or may under-report symptoms, if they think their personal information will be disclosed".

\section{IMPLICATIONS FOR HEALTHCARE ACCESS}

While there is great demographic and health variation among migrants in the UK, some groups such as undocumented migrants, refugees and asylum seekers and children, are especially vulnerable. Marginalised migrants already face numerous barriers to accessing care, from poor English, unfamiliarity with the UK healthcare system and wariness of engaging with any authorities, including doctors. ${ }^{4}$ The charging regulations are complex and not easily understood, so fear of being charged, even for exempted services, compounds these problems.

Sexual health services are a particularly interesting area of focus, because they are exempt from charging on public health grounds to make them more accessible. Despite this, take up of these services is already affected by stigma surrounding sexually transmitted infections (STIs) and fear of life-threatening conditions such as HIV. There are few specific data on migrant access to sexual health services, but there is evidence of widespread ignorance and confusion about the charging rules, even among NHS staff. ${ }^{5}$ It is therefore likely that undocumented or otherwise vulnerable migrants will be deterred from accessing sexual health services in spite of the exemption, especially as the data-sharing arrangement contributes to a wellgrounded fear of immigration enforcement.

Sharing patient information with the Home Office undermines the ability of doctors to reassure patients that they are not government agents, that information about their health is confidential, and that it is safe to talk openly to healthcare workers. Fear of immigration enforcement already discouraged people from seeking care before these latest changes; indeed Doctors of the World report that even before the data-sharing arrangement became public, $10 \%$ of the patients they saw had avoided NHS services because of fears of immigration enforcement, while some migrants now say they will avoid registering with primary care. ${ }^{3}$ The parliamentary Health Select Committee heard testimony about a woman who died of pneumonia after not seeking care. ${ }^{6}$ There will be myriad other cases, many of which we will not hear about because undocumented migrants are inherently less visible to public services.
The arrangement has been condemned by doctors and organisations working in these areas. After holding hearings on the subject, the chair of the Health Select Committee, Dr Sarah Wollaston, wrote to the head of NHS Digital to request them to withdraw immediately from the agreement and carry out a full review of the effects of such a policy. In her letter, she noted that there is "no mention anywhere in the MoU of the public interest in the maintenance of a confidential medical service", and that the "NHS should not place" the Home Office's need for information for immigration enforcement "above the serious adverse consequences of such a decision". 7 At the time of writing NHS Digital had rejected this call. [Editor's Note. The government announced in May 2018 that the MoU was to be revised to restrict the data-sharing arrangement.]

Although primary care is currently not chargeable, the charging and data-sharing policies are eroding the distinction between the health service and other government authorities. With reports, for example, of general practitioners (GPs) being sent deportation letters to pass on to patients, ${ }^{8}$ reasons why people may be wary of seeking care are clear.

The likely consequence is that people who may be unable to pay will actively avoid seeking care, ultimately presenting late, with negative consequences for their health. Treatment at a later stage, when people are more ill, is also more complex and expensive, putting greater strain on NHS budgets. ${ }^{3}$ Prevention is better than cure, both for patients and health service costs. Policies that act as a deterrent to engaging with sexual health services run counter to efforts to prevent the spread of STIs and to reduce unwanted pregnancies.

Many STIs are asymptomatic and may be detected on routine investigations or when assessing other issues. But if patients are too scared even to visit a doctor, these opportunities will be missed. Many migrants struggle just to register with a GP.

\section{HIV}

The risk of deterrence is especially pertinent in HIV care as many new diagnoses are in non-UK-born patients. Public Health England figures show that "in 2016, for all those for whom country of birth was known, 55\% of people newly diagnosed with HIV were migrants. $55 \%$ of all people seen for HIV care in England are migrants". ${ }^{3}$ Furthermore, while 42\% of HIV diagnoses in 2016 were made at a late stage of infection, these figures rise to $65 \%$ and $49 \%$ for black African heterosexual men and women, respectively. ${ }^{9}$

It is also interesting to note that while the charging exemption now covers HIV treatment, this was not exempted when overseas visitor charging was introduced in 2004; only in October 2012, after a long campaign, was HIV treatment made free for all patients. People may be unaware of this change, which could affect their accessing HIV services and contribute to the higher rates of late diagnosis among migrants. 


\section{Sex workers}

Sex workers are at high risk of contracting STIs. Studies shortly before the 2014 changes to the Immigration Act showed that both male and female sex workers attending genitourinary medicine clinics in England are more likely to be migrants. ${ }^{10} 11$ While the care provided is still free at the point of use, fear of charging and of data sharing may lead to a reversal in the pattern seen in these studies, whereby migrant sex workers become less likely to attend sexual health clinics.

\section{Reproductive health}

For reproductive healthcare, the situation is similarly complex. Family planning services are exempt from charging, but termination of pregnancy is not and ineligible patients must pay. ${ }^{2}$ Meanwhile, the regulations class all antenatal services as 'immediately necessary', meaning patients must not be denied care because of an inability to pay. Instead, after the birth women whom the hospital finds to be eligible for charging receive a bill for $150 \%$ of the cost to the NHS of their care - potentially for thousands of pounds for even an uncomplicated delivery. This can leave women in an impossible position of being unable to afford either option - continuing with a pregnancy or terminating it. The contradictions in these policies take away women's control over their reproductive health, which is particularly concerning given the risks of sexual violence and exploitation that undocumented migrant women face. ${ }^{12}$

In addition, these policies can leave marginalised migrant patients with debts they have no ability to pay, and migrants with debts to the NHS may then have their immigration case refused on the grounds of their debt. In a further complication of reproductive healthcare access, assisted conception services such as in vitro fertilisation are always chargeable, even for patients who have paid the health surcharge. ${ }^{2}$

Charities working in this area have found that fear of charging contributes to pregnant women presenting late, putting their and their fetus's health at risk. In one study at a London clinic that helps undocumented migrants to access care, a quarter of pregnant women had not accessed antenatal care by 18 weeks. ${ }^{13}$ There is limited research into the reasons for presenting late. However, in another study of migrants attending a Doctors of the World clinic, fears about costs emerged as a major concern for those who had delayed seeking healthcare, including antenatal care. ${ }^{14}$

\section{Health inequalities}

By reducing or delaying care, these policies widen health inequalities. A 'healthy migrant' effect has been documented, in which people arrive in better health than would be expected, but their health declines after arrival. ${ }^{4}$ However, undocumented migrants are among the most vulnerable to disease - whether that be from overcrowded or precarious housing, poor nutrition, or poverty. As they are unable to work legally or claim benefits, undocumented migrants are highly marginalised and affected by the multiple socio-economic determinants of ill-health. ${ }^{4}$ In addition, they may be sex workers or may have experienced sexual violence or trafficking, and they may have complex medical and psychological problems such as post-traumatic stress disorder.

Given the difficulties of engaging with these groups, adding extra barriers as these policies do, is highly detrimental to their care. The challenges of establishing a history of sexual trafficking or sexual violence are well documented, with evidence that staff already lack the skills necessary to identify and support these patients. ${ }^{15}$ The new system adds further complexities, with patients being even more hesitant to engage with healthcare professionals or to disclose their history, and ill-equipped staff trying to determine which services they can provide without risk of charging and whether medical records might be disclosed to the Home Office.

Good sexual health is important for public health. By deterring patients from seeking care, their health is endangered, with some easily treated conditions having long-term sequelae if untreated, and also putting the wider public at risk. Late presentation in general leads to poorer outcomes, and endangers patients, their sexual partners, and with some vertically transmitted infections may also put babies at serious risk. Motherto-child transmission of HIV is very rare in Britain, ${ }^{9}$ but this could change if women are wary of accessing care because of fears about charging or data sharing.

\section{CONCLUSIONS}

As they are generally exempt from charges, SRH services are not considered to be at the forefront of the 'hostile environment' to migrants that has been imposed on the NHS. However, as services of particular importance to general health, and to which it is important that migrants have access, the implications if people are put off accessing care because of their perceptions about charging and data sharing are a serious cause for concern. Charges create a significant additional barrier to marginalised migrants accessing care in an area where there are already multiple hurdles for people to overcome. Ultimately this undermines the purpose of the exemption from charging, the protection of public health.

Charging contravenes the ethical principles that healthcare students imbibe from their first days of training, with regular reports of demonstrable harm being caused. These policies are entrenching health inequalities faced by migrants in the UK, limiting access to care to those who can pay, and endangering individual and public health.

Some of these patients are among the least able to navigate the system, to advocate for themselves to 
secure the care they need. It is the role of healthcare professionals working in the NHS to support patients to receive that care. Staff working in SRH cannot allow themselves to be complacent that their services will be unaffected by these policies, given the barriers they pose to access to care by some of the most marginalised patients.

Competing interests None declared.

Patient consent Not required.

Provenance and peer review Not commissioned; externally peer reviewed.

Author note This is an edited version of the author's original prize-winning entry for the Faculty of Sexual \& Reproductive Healthcare's 2018 Margaret Jackson Essay Prize for undergraduate medical students.

\section{REFERENCES}

1 Faculty of Sexual \& Reproductive Healthcare. About us. https://www.fsrh.org/about-us/ (accessed 23 Mar 2018).

2 Department of Health, 2017. Guidance on implementing the overseas visitor charging regulations. https://www.gov. uk/government/uploads/system/uploads/attachment_data/file/ 666031/UPDATED_Guidance_to_Charging_Regulations_post 23 October.pdf (accessed 23 Mar 2018).

3 National Aids Trust and Doctors of the World, 2017. Written evidence to Health Select Committee. http://data.parliament. $\mathrm{uk} /$ writtenevidence/committeeevidence.svc/evidencedocument/ health-and-social-care-committee/memorandum-ofunderstanding-on-datasharing-between-nhs-digital-and-thehome-office/written/76525.html (accessed 23 Mar 2018).

4 Migration Observatory, 2014. Health of migrants in the UK: what do we know? http://www.migrationobservatory.ox.ac.uk/ resources/briefings/health-of-migrants-in-the-uk-what-do-weknow/ (accessed 23 Mar 2018).

5 Medact Manchester, 2017. Healthcare professionals' views and experiences of dealing with refugees and asylum seekers: a survey of North-West practitioners. https://medactmanchester. files.wordpress.com/2017/10/medact_report_2017.pdf (accessed 23 Mar 2018).

6 House of Commons, 2017. Oral evidence: Memorandum of understanding on data-sharing between NHS Digital and the Home Office, HC 677. http://data.parliament.uk/ writtenevidence/committeeevidence.svc/evidencedocument/ health-and-social-care-committee/memorandum-ofunderstanding-on-datasharing-between-nhs-digital-and-thehome-office/oral/77354.html (accessed 23 Mar 2018).

7 Wollaston S. Letter to Sarah Wilkinson, Chief Executive, NHS Digital, regarding sharing of patient address information with the Home Office for immigration enforcement purposes. 2017 https://publications.parliament.uk/pa/cm201719/cmselect/ cmhealth/Correspondence/Wilkinson-2018-01-29.pdf.

8 GP Online. Immigration agency asked GP to deliver deportation notice to patient. https://www.gponline.com/ immigration-agency-asked-gp-deliver-deportation-noticepatient/article/1457721 (accessed 23 Mar 2018).

9 Public Health England, 2017. Towards elimination of HIV transmission, AIDS and HIV-related deaths in the UK. https:// www.gov.uk/government/uploads/system/uploads/attachment_ data/file/675809/Towards_elimination_of_HIV_transmission_ AIDS_and_HIV_related_deaths_in_the_UK. UK.pdf (accessed 23 Mar 2018).

10 Mc Grath-Lone L, Marsh K, Hughes G, et al. The sexual health of female sex workers compared with other women in England: analysis of cross-sectional data from genitourinary medicine clinics. Sex Transm Infect 2014;90:344-50.

11 Mc Grath-Lone L, Marsh K, Hughes G, et al. The sexual health of male sex workers in England: analysis of crosssectional data from genitourinary medicine clinics. Sex Transm Infect 2014;90:38-40.

12 Geddie E. Undocumented migrant women; 2014. Gunda Werner Institut. https://www.gwi-boell.de/de/node/23267 (accessed 23 Mar 2018).

13 Ockert-Axelsson H, 2017. Sick and tired, and afraid: assessing the relationship between unpaid hospital bills and the consequences debt can have on immigration status for undocumented migrants at an East London charity clinic. https://www.doctorsoftheworld.org.uk/Handlers/Download. ashx? IDMF = c5e794a1-8c30-4457-a096-2da02fd14ed0 (accessed 23 Mar 2018).

14 Quy J, 2017. What are the experiences of vulnerable migrants when accessing secondary healthcare in the United Kingdom? https://www.doctorsoftheworld.org.uk/Handlers/Download. ashx?IDMF $=8$ f 735eb1-d357-4df5-9723-cf7081bda719 (accessed 23 Mar 2018).

15 Ross C, Dimitrova S, Howard LM, et al. Human trafficking and health: a cross-sectional survey of NHS professionals' contact with victims of human trafficking. BMJ Open 2015;5:e008682. 